\title{
The effect of body mass on the mass specific metabolic rate of Pseudemoia entrecasteauxii and Eulamprus quoyii
}

\author{
Yvonne Yong, Ainsley Maurer, Caitlin McLeod, You Zhou
}

\section{Abstract}

Measuring metabolic rate is important to understand energy acquisition, transfer and expenditure within an organism. Mass specific metabolic rate is also known as metabolic intensity. The metabolic intensities of Pseudemoia entrecasteauxii and Eulamprus quoyii were measured within a closed system through the amount of oxygen depleted when at rest. There was found to be a negative correlation between the mass of the skink and the metabolic intensity, or the oxygen consumption per hour. The average mass of $P$. entrecasteauxii was found to be lower than E. quoyii, and P. entrecasteauxii was found to have a lower metabolic intensity than $E$. quoyii, which follows Kleiber's law. The difference in metabolic intensity may be influenced by the climate of the microhabitats that the skinks live in.

\section{Introduction}

All animals have chemical processes within them that keep them alive. Such processes include cell growth, brain and nerve function and respiration (Parry 1983). Metabolism is the term used to describe these processes of energy transactions that occur throughout the body and how the energy is transformed within the organism and the environment (Gillooly 2001).

The mass of an animal affects the rate of metabolism and this relationship is known as the mass specific metabolic rate, or metabolic intensity. This relationship is quantified by Kleiber's law (Kleiber 1947), which proposes that larger sized animals use less energy per cell to sustain their needs (Kalra et al. 2013). Kleiber's law states that metabolic rate of the organism increases at a rate proportional to its mass to the power of 0.75 , which 
means that larger animals have a lower metabolic rate per unit mass compared to smaller animals. Thus, there is a negative correlation between the metabolic rate per unit mass, also known as metabolic intensity, and mass (Kleiber 1947). This means that smaller organisms have a higher metabolic rate per unit mass compared to larger organisms.

The measurement of metabolic intensity, and hence metabolic rate, is important to describe energy acquisition, transfer or expenditure within an organism. This can be done through measuring oxygen consumption (Weir 1949). Measuring oxygen consumption is a common method to measure metabolic rate. Within all vertebrates respiration is mainly aerobic, meaning they consume molecular oxygen for cellular respiration. The assumption is made that oxygen consumption is an estimate of the rate of energy metabolism (Schmidt-Neilsen 1990; Speakman 2013).

To measure the oxygen consumption, and hence the metabolic rate, a closed system is often used as the decline in oxygen is easily measureable. The organism is measured at rest to find out the standard metabolic rate (or basal metabolic rate in endotherms). Standard metabolic rate is what the minimum metabolic rate is to sustain the organism's life at the certain temperature.

Ectotherms have their standard metabolic rate dependent upon the surrounding temperature. Skinks are an example of an ectothermic animal. Skinks can be found in a wide range of habitats, including the Australian alpine region. Two such species that are found in the Australian alpine region are Pseudemoia entrecasteauxii (mountain log skink) and Eulamprus quoyii (eastern water skink). Pseudemoia entrecasteauxii can be found in a variety of preferably sunny habitats, such as on rocks and north-west aspects (Jellinek et al. 2004), whereas E. quoyii are commonly found nearby creeks or moist areas (Law and Bradley 1990). The unique microhabitats that these species live in reflect their optimal temperatures, at which their metabolic rates are at their highest. It would be assumed that $E$. quoyii has a lower optimal temperature based upon its microhabitat of near moist areas, as they would be cooler. Similarly, based upon the microhabitat of $P$. entrecasteauxii, it would be assumed that their optimal temperature is higher than that of E. quoyii. 
The main aim of the experiment is to compare the metabolic intensities of the two skink species, P. entrecasteauxii and E. quoyii. This is explored by investigating the effect body size has upon the metabolic intensity as well as how the habitats of the skinks affect their optimal temperatures and therefore their metabolic intensities at a given temperature.

The predicted comparison of metabolic intensities of $P$. entrecasteauxii and E. quoyii is that $P$. entrecasteauxii should have a lower metabolic intensity compared to E. quoyii. This is because they are smaller organisms and their optimal temperature may be further from the ambient experimental temperature than that of E. quoyii.

\section{Methods}

The skinks were all caught around Rainbow Lake in Kosciuszko National Park on 9 and 11 December 2015. There were eight Pseudemoia entrecasteauxii and seven Eulamprus quoyii. The P. entrecasteauxii were caught on 9 December whereas the E. quoyii were caught on 11 December, both around 9 am to $12 \mathrm{pm}$. The weather on both days was sunny and slightly windy; however, it should be noted that 8 December had severe rain while 10 December had pleasant weather. The experiments were completed the day after capture and the skinks were placed back where they were caught on the day when experiments were completed. The skinks were caught by using mealworms to entice them within range of capture by hand. The skinks were housed separately in containers $(-8 \mathrm{~cm}$ $\times 13 \mathrm{~cm} \times 25 \mathrm{~cm}$ ) with mulch, some water in a bottle cap and a cardboard tube for shelter. For the duration of the experiments, the skinks were not given any food.

The equipment used for measuring oxygen consumption was the Firesting Oxygen fibre-optic oxygen meter with Pyro-Science Oxygen Logger Software version $>3.2$. Four custom-built chambers were used in each trial and had Pyro-Science Contactless Fibre-Optic Oxygen Sensor Spots inside. Pyro-Science Basic Spot Adapters were attached on top of the spots using sticky tape and a needle was used to make a hole for the sensor. The chambers were calibrated to a stable amount of oxygen, which was as close to 21 per cent as possible, and the ambient temperature during experiments was kept at $17.5^{\circ} \mathrm{C}$ to $18.5^{\circ} \mathrm{C}$ through the use of a heat lamp. At night, the lamps were turned off to simulate the night environment and to keep the skinks less active. 
The lizards were numbered in order of capture and the order in which they would be placed in the chambers was randomised using the random number generator implemented in Microsoft Excel. The chamber sizes used were $220 \mathrm{~mL}$ and $380 \mathrm{~mL}$. The $220 \mathrm{~mL}$ chambers were used for P. entrecasteauxii and the $380 \mathrm{~mL}$ were predominantly used for the E. quoyii.

The lizards' oxygen consumption was measured at rest inside the chambers for 15 minutes. The measurement started when the skink was no longer breathing heavily, and if the oxygen percentage within the chamber lowered by 3 per cent or more within the 15-minute timeframe, the experiment would be stopped for that chamber due to a lack of oxygen. Furthermore, the skinks' behaviours were noted while in the chambers and during the transfer between the containers and chambers.

Three experiments were conducted for each lizard and their masses weighed. The data were averaged and the metabolic intensity calculated. The units used for metabolic intensity are $\mathrm{mL}$ of oxygen/gram/hour. The metabolic intensities (MI) of the skinks was calculated using the following formula:

$M I=\left(\left(\right.\right.$ Start $O_{2} \%-$ Finish $\left.\mathrm{O}_{2} \% \times 100\right) \times(($ Chamber Volume - Skink Mass $\left.) \times 4)\right)$

(Mass of Skink)

\section{Results}

We found a negative correlation between the mass of the skink and the average oxygen consumption (Figure 1). Pseudemoia entrecasteauxii does not have a strong negative correlation between its mass and the oxygen consumption (Figure 1c), particularly when compared with Eulamprus quoyii, which has a stronger negative correlation between the mass and oxygen consumption. Furthermore, the average mass of $E$. quoyii is higher than that of $P$. entrecasteauxii (Figures $1 \mathrm{a}$ and $1 \mathrm{~b}$ ). When compared logarithmically, the correlation between the mass of P. entrecasteauxii and its metabolic intensity is not as strong as the correlation of mass and metabolic intensity of E. quoyii (Figure 1c). The strength of the correlations can be seen through the R-squared values (Figure 1c). Pseudemoia entrecasteauxii has an R-squared value of 0.7084 whereas $E$. quoyii has a value of 0.91823 . A logarithmic comparison of the metabolic intensities between the two skinks shows that $E$. quoyii has a higher metabolic intensity than that of $P$. entrecasteauxii. In addition to this, the $P$. entrecasteauxii has a trend line lower than that of the E. quoyii (Figure 1c). 
Skinks were observed to be heavily breathing and some were still moving around during the experimentation, which were often signs of stress. The skinks with a larger mass were observed to have a tendency to escape when the enclosures were opened.

a)

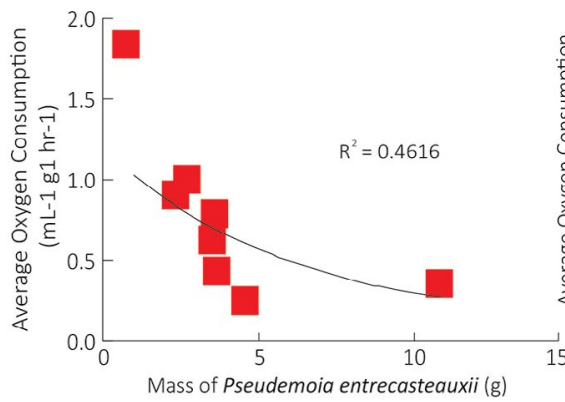

Eastern Water Skinks

c)

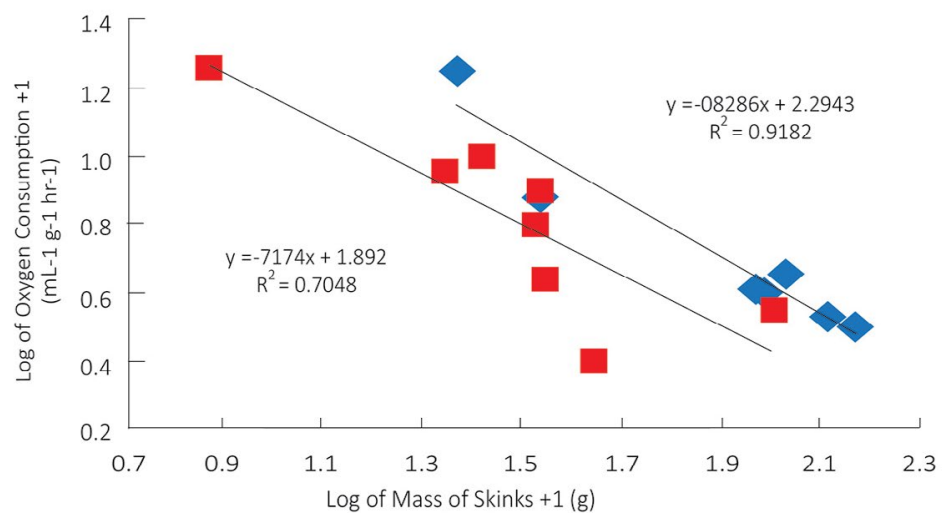

b)

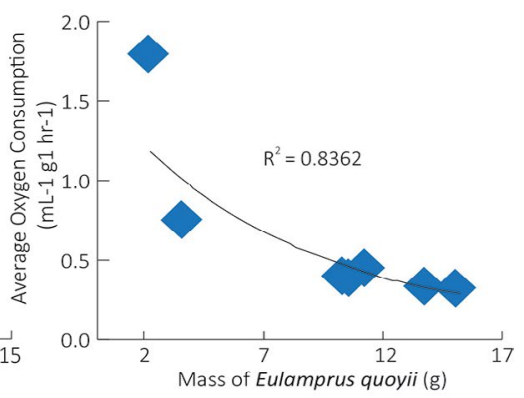

Figure 1: Average oxygen consumption of a) Pseudemoia entrecasteauxii, and b) Eulamprus quoyii as a function of body mass, c) log of the mass of the skinks +1 against the log of oxygen consumption +1 at $18^{\circ} \mathrm{C}$.

Note: The blue diamond plots are for $E$. quoyii and the red square plots are $P$. entrecasteauxii. All the data points had 1 added to them to give positive values.

Source: Authors' data. 


\section{Discussion}

The results show a trend for larger $P$. entrecasteauxii and $E$. quoyii to have a lower metabolic intensity than smaller-sized P. entrecasteauxii and E. quoyii (Figures $1 \mathrm{a}$ and $1 \mathrm{~b}$ ). This is seen through the negative correlation between the oxygen consumption and the mass of the skink. The comparison of both $P$. entrecasteauxii and E. quoyii on a logarithmic scale (Figure 1c) shows that $P$. entrecasteauxii has a lower metabolic intensity than $E$. quoyii at the ambient temperature of approximately $18^{\circ} \mathrm{C}$. The average body size of $P$. entrecasteauxii can also be seen to be less than that of $E$. quoyii within Figure 1c. The results agree with Kleiber's law, which states that there should be a negative correlation between metabolic rate per unit against body size (Kleiber 1947). The lower metabolic intensity and the smaller average body size of $P$. entrecasteauxii agrees with Kleiber's law that states smaller body sizes correlates to a lower metabolic intensity (Kleiber 1947). Furthermore, the lower metabolic intensity of $P$. entrecasteauxii may suggest that they have a higher optimal temperature, reflected by their habitats of sunnier, warmer areas when compared to E. quoyii.

The results show a trend for larger $P$. entrecasteauxii and $E$. quoyii to have a lower metabolic intensity than smaller sized $P$. entrecasteauxii and E. quoyii (Figures 1a, 1b). This is seen through the negative correlation between the oxygen consumption and the mass of the skink. The comparison of both $P$. entrecasteauxii and E. quoyii on a logarithmic scale (Figure 1c) shows that $P$. entrecasteauxii has a lower metabolic intensity than $E$. quoyii at the ambient temperature of approximately $18{ }^{\circ} \mathrm{C}$. The average body size of $P$. entrecasteauxii can also be seen to be less than that of $E$. quoyii within Figure 1c. The results agree with Kleiber's law, which states that there should be a negative correlation between metabolic rate per unit against body size (Kleiber 1947). The lower metabolic intensity and the smaller average body size of $P$. entrecasteauxii agrees with Kleiber's law that states smaller body sizes correlates to a lower metabolic intensity (Kleiber 1947). Furthermore, the lower metabolic intensity of P. entrecasteauxii may suggest that they have a higher optimal temperature, reflected by their habitats of sunnier, warmer areas when compared to E. quoyii.

There were many limitations encountered when gathering and processing the field data. These include time constraints when allowing the skinks to rest before chambers were closed to begin the timing of oxygen depletion. 
Chambers were closed when the skinks were still heavily breathing to reduce the time needed for each trial. This could have led to skewed results because the skinks are inhaling more oxygen than if they were at rest.

The many assumptions required were also a limitation when processing the data. These assumptions include that the skinks were fasting, were not gravid, were of good health, were all similar ages, that the ambient temperature was consistently kept between $17.5^{\circ} \mathrm{C}$ and $18.5^{\circ} \mathrm{C}$ and that the same amount of oxygen results in the same amount of ATP. Obvious amendments to the method of the experiment would be doing the experiments in better-controlled areas of temperature and have consistent health of the skinks. The stage of fasting within the skinks could be controlled by having the skinks captive for a longer period of time, ensuring that the skinks are fed the same diet for a set amount of time before fasting them.

There have been no previous measurements of the metabolic intensities measured through oxygen depletion using a closed system for $P$. entrecasteauxii and E. quoyii. Further research to explore the metabolic intensities of the skinks includes investigating the microhabitats in which P. entrecasteauxii and E. quoyii are found, which can assist in determining the optimal temperatures for species based upon their habitats. Similarly, a study of the skinks' enzymatic activities can be done to further investigate the optimal temperatures within P. entrecasteauxii and E. quoyii.

\section{Acknowledgements}

We acknowledge the Research School of Biology of The Australian National University and especially Adrienne Nicotra for making the BIOL2203 course a reality, Phillipa Beale for guiding the group through the experiment, William Foley for guidance through the write up, and rangers and staff of Kosciuszko National Park for permission to collect organisms and experiment within the park.

\section{References}

Gillooly JF (2001) Effects of size and temperature on metabolic rate. Science 293: 2248-51. doi.org/10.1126/science.1061967 
Janzen, DH (1967) Why mountain passes are higher in the tropics. The American Naturalist 101(919): 233-49.

Jellinek S, Driscoll DA, Kirkpatrick JB (2004) Environmental and vegetation variables have a greater influence than habitat fragmentation in structuring lizard communities in remnant urban bushland. Austral Ecology 29: 294-304. doi.org/10.1111/j.1442-9993.2004.01366.x

Kalra S, Shah S, Sahay R (2013) Kleiber's law and the A chieve study. Indian Journal of Endocrinology and Metabolism 17: 397. doi. org/10.4103/2230-8210.122039

Kleiber M (1947) Body size and metabolic rate. Physiological Reviews 27: 511-41.

Law BS, Bradley RA (1990) Habitat use and basking site selection in the water skink, Eulamprus quoyii. Journal of Herpetology 24: 235-40. doi. org/10.2307/1564388

Parry GD (1983) The influence of the cost of growth on ectotherm metabolism. Journal of Theoretical Biology 101: 453-77. doi. org/10.1016/0022-5193(83)90150-9

Schmidt-Nielsen K(1990) AnimalPhysiology: Adaptation and Environment, 4th edn. Cambridge University Press, Cambridge.

Speakman JR (2013) Measuring energy metabolism in the mouse theoretical, practical, and analytical considerations. Frontiers in Physiology 4. doi.org/10.3389/fphys.2013.00034

Weir JBdeV (1949) New methods for calculating metabolic rate with special reference to protein metabolism. The Journal of Physiology 109: 1-9. doi.org/10.1113/jphysiol.1949.sp004363 
This text is taken from Researching functional ecology in Kosciuszko National Park, edited by Hannah Zurcher, Chia Ming-Dao, Michael Whitehead and Adrienne Nicotra, published 2017 by ANU eView, The Australian National University, Canberra, Australia. 